\title{
INTERCULTURAL BUSINESS DISCOURSE: CHARACTERISTICS OF KAZAKH CONTEXT
}

\author{
Buadat Karibayeva $^{1^{*}}$ and Salima S. Kunanbayeva ${ }^{2}$ \\ ${ }^{1}$ MA, Kazakh Ablai khan University of International Relations and World Languages, The Republic \\ of Kazakhstan, buadat@gmail.com \\ ${ }^{2}$ Prof. Dr., Kazakh Ablai khan University of International Relations and World Languages, The \\ Republic of Kazakhstan, rector@ablaikhan.kz \\ ${ }^{*}$ Corresponding author
}

\begin{abstract}
Many cross-cultural business interactions quite often constitute a source of cultural misinterpretations and misconceptions. Typically each party uses native strategies to communicate across groups. Different cultures also use their own methods to interpret verbal and non-verbal messages. Therefore, developing a deeper understanding of cross-cultural communicational preferences is critical for any successful international business venture, which stems active research interest in this area. This article, in particular, focuses on a comparative analysis of Kazakh business communication style against different established communication patterns across the globe, e.g. a tendency towards following collective cultural patterns within Kazakh community with resulting implications on the importance of space and privacy, relational and collaborative business inclinations, and intuitive communication style preferences. The article also covers the significance of age and preferences. Finally, cultural roots for preferred communication channels, directness, writing clarity and conciseness in Kazakh business discourse are explained. Often it is the historical development of the community that shapes the mentality, styles of spoken and written communication, as well as methods of interpreting messages from other cultures. These trends are demonstrated on the development of modern Kazakh business discourse preferences and traits. Overall, the article shows that it is not only important to be aware of differences in cultural communication conceptions, but even more important to recognize them, place and interpret the message within the right cultural context. This work aims to present a well-rounded overview of Kazakh business discourse preferences, serving as a guideline for cross-cultural business communication as well as an important contributing piece to the field of intercultural studies.
\end{abstract}

Keywords: Business Discourse, Intercultural Communication, Kazakh communication preferences.

\section{INTRODUCTION}

We live in the era of instant communication, where internet and accessible international travels are pushing numbers of cross cultural interactions to historically unprecedented frequencies. These interactions can often 
result in cultural assimilation, e.g. adoption of Christmas celebrations in China, Japan, and Korea. At the same time, cross cultural exchange frequently opens new international business opportunities. A striking example of such business ventures is the expansion of KFC to Japan, whose bucket of chicken is now exclusively linked to Christmas celebration in the country (Kimura \& Belk, 2005, Liebheit, 2013). As the number of multinational companies and new international business ventures grows, so does the necessity to communicate more effectively across cultures.

As a result, intercultural business discourse has become a subject of extensive research interest. While some authors take on business discourse research and exploration in a more global sense (Søderberg \& Holden, 2002, Bargiela-Chiappini, Nickerson, \& Planken, 2013, Johnson, Lenartowicz, \& Apud, 2006), many others consider specific case studies of cross-cultural business interactions (Yamada, 1992, Yli-Jokipii, 1994, Park, W. Tracy, \& Kenneth L., 1998). This paper provides a brief overview of business discourse in Kazakh context. In particular, it discusses global cultural discourse trends and places Kazakh cultural preferences in that framework.

\section{CULTURAL CHARACTERISTICS}

Most cultures across the globe can be roughly classified into either individualistic or collective culture groups (Reynolds \& Valentine, 2011). Even though this classification is not absolute and some cultures might not fit either category, it is a useful exercise to discuss typical characteristics of individualistic and collective cultures before elaborating on specifics of Kazakh society.

In individualistic cultures people are brought up to be independent of one another. This means that each person is ultimately responsible for their own life decisions, and the majority of choices are made to benefit the individual. A typical characteristic of an individualistic culture is that individual's needs and rights are more important than the needs of the group. Therefore, in the majority of western cultures (e.g. North America and Europe) key professional and personal life decisions, like selection of marriage partners or a career choice, are ultimately made by each person independently (Reynolds \& Valentine, 2011).

Space and privacy have great value in individualistic cultures. This can be readily observed in a typical arrangement of home and office space. Even though couples would normally share a bedroom, each individual would aim to have a personal 'corner' inside the house. As a result, garage spaces and basements are often rearranged into offices or craft rooms. In the office environment, private offices are preferred to cubical arrangements. People place great value on personal space and time. Most business meetings are arranged in advance while unannounced visits to the office are rarely encouraged. Typical examples of unspoken rules in individualistic office environment would include the following. A closed office door means that a person does not wish to be disturbed at the moment, and people typically do not initiate business discourse in the office hallways. Entering an office without knocking is frowned upon.

Individualistic cultures are often associated with a result-driven business style; therefore quantifying success in profit, efficiency, and market value is a common practice. A business decision is typically assessed quantitatively, and whenever a new business venture or collaboration is being agreed upon, the deal is only considered binding after the legal paperwork is signed. Business and personal relationships are kept separate, and this principle is embedded in the very definition of professionalism in individualistic cultures. Personal relationships are seen as obstacles to unbiased professional judgment and can even be viewed as a cause for the conflict of interests. Hence, co-workers rarely establish close friendship and socialize with each other only occasionally, simply to maintain cordial business relationships and atmosphere.

Collective cultures, on the other hand, place greater importance on groups rather than individuals. Members of collective cultures see themselves as elements in a closely-knit network with others; they are part of a strong cohesive unit (family, clan, profession, corporation, religion) that protects and supports them throughout their lives in exchange for their loyalty (Reynolds \& Valentine, 2011). As a result, all major personal decisions would be made after consulting the group at large. For example, family is often heavily involved in selection of marriage partners - in countries like India, Bangladesh, Mongolia and Uzbekistan arranged marriages are common place.

Personal relations are valued well above privacy and personal space both at home and in office environments. It is common for people to live in extended families, and there seems to be less emphasis on having private rooms. In terms of the office environment, private offices and cubical arrangements are not always favoured and people tend to work in open group stations. As a result, discussing business matters in the hallways and public spaces is common place, and unannounced visits to the workplace are not discouraged.

In collective cultures, personal relationships can be valued more than quantitative data in making business 
decisions. Even though numerical data is not ignored when building business arguments, it is also important who the argument is coming from. A great deal of emphasis can be placed on loyalty and trust when making decisions.

Kazakh culture was built upon a long standing nomadic history and lifestyle. People traditionally lived in close groups and extended families, which moved throughout the year to maintain large numbers of livestock. The biggest challenge to a traditional nomadic culture was overcoming difficulties posed by the harsh climate of Central Asia. Therefore, the society was built in such a way that each individual played well defined roles in the community as a whole. As a result, Kazakh culture shares a lot of common attributes with the collective cultures.

Much alike to collective cultures, Kazakh individuals have a strong sense of 'face' or personal dignity. As a result, many of the personal life choices are often weighed against public opinion. This includes both professional choices as well as personal ones, like selecting a marriage partner. In particular, it is a common practice to consult on major decisions with the Elders (Uzakbaeva \& Beisenbayeva, 2015) who traditionally hold a special role within the community. In Kazakhstan, age is a symbol of wisdom. Advanced age earns special respect. Kazakh people consider that there are a lot of things to be learnt from elder people. Their life experience is worth of sharing. The elders' advice is a pearl of wisdom.

At the same time, there are a few attributes that Kazakh society shares with individualistic cultures as well. For example, there is a preference for private space both at home and offices. Private offices are considered a reflection of status. Furthermore, similarly to individualistic cultures, each individual is expected to speak for themselves and speak freely. This comes from the fact that historically Kazakh community would elect their clan leaders and representatives to the judicial systems, and people traditionally enjoyed the freedom of speech. However, it was practiced more by respected elderly population, rather than youth.

As an old Kazakh proverb goes, "Roots make trees strong; friends make people strong". This proverb highlights the importance of personal relations in business interactions. This is another attribute that Kazakh culture shares with the group of collective cultures. Building trust and loyalty with business partners and coworkers is a crucial part of business interactions. Decision-making process often takes into account not only the immediate benefits but also the long-term goals and implications on personal-professional relations. As a result, it is a common practice for business partners and co-workers to socialize outside professional environments. For example, people often invite professional connections to their home for dinner in order to establish trusting bonds.

\section{WRITING COMMUNICATION PREFERENCES}

Even though the majority of written business communication across the globe is conducted in English, differences in writing styles across cultures can be significant. While some cultures prefer clear and direct messages, others consider them impolite and adhere to a more indirect communication style in writing. Therefore, understanding these communicational and cultural preferences can be crucial in having productive cross-cultural business interactions.

The very structure of English writing, where thesis statements declare the main message of the letter and the passage, is built around delivering information directly. Getting right to the point is considered a good writing style and is often an indication of openness, sincerity, and clear thinking. Fundamental blocks of a letter written in English are introduction, body, and conclusion. Introductory paragraphs and sections necessarily state the main purpose of writing and often provide synopsis for the upcoming sections and paragraphs. Body paragraphs are typically reserved for the qualitative and factual support of the main message and often include examples and more detailed explanations. Concluding parts of written communication reiterate the main message and highlight main supporting details.

There are several additional features of English writing worth of mentioning. The use of passive voice is typically avoided since it is often associated with the lack of conviction in the message. Moreover, English writers are more inclined to using "I" in their writing rather than "we". This is related to the sense of accountability for the message.

Although, most Kazakh professionals are fairly comfortable with written English, indirect messages are prevalent in written business discourse. This is true when messages are written in both Kazakh and English languages. Since relationships are valued highly in the professional environment, letters often start with courtesy messages and seemingly unrelated information. Similarly to many other eastern cultures, Kazakh writers often feel the need to include background information and context before delivering the main message. Therefore, letters typically have the structure that carries more weight towards the end of the written communication. The tendency to include background information and context in written 
communication adds significantly to the length of letters written by Kazakh professionals, compared to letters written by native English speakers.

Furthermore, a Kazakh writer would often be inclined to using passive voice in written discourse. "We" tends to be used instead of "l", conveying a sense of collaborative inclusion.

\section{CONCLUSION}

Overall, Kazakh community fits the collective cultural group, similarly to many other eastern cultures. Individuals in Kazakh culture maintain a strong sense of 'face', personal dignity, and respect for elders within the community. Business style is highly collaborative, with significant importance placed on developing and maintaining personal relationships. As a result, in writing Kazakh writers prefer indirect messaging and using passive voice, which are often considered a polite manner of writing. These writing preferences are directly linked with the desire to foster personal relationships in business interactions. Even though the study of cross cultural business discourse has been active for few decades, comparative research of Kazakh business discourse is fairly new and needs further investigation.

\section{REFERENCE LIST}

Bargiela-Chiappini, F., Nickerson, C., \& Planken, B. (2013). Business discourse. Palgrave Macmillan.

Johnson, J. P., Lenartowicz, T., \& Apud, S. (2006). Cross-cultural competence in international business: Toward a definition and a model. Journal of International Business Studies, 525-543.

Kimura, J., \& Belk, R. W. (2005). Christmas in Japan: Globalization versus localization. Consumption Markets \& Culture, 325-338.

Liebheit, M. (2013). KFC and Christmas cake-Christmas in Japan. JapanSociology.

Park, M. Y., W. Tracy, D., \& Kenneth L., M. (1998). Korean business letters: Strategies for effective complaints in cross-cultural communication. Journal of Business Communication, 328-345.

Reynolds, S., \& Valentine, D. (2011). Guide to cross-cultural communication. New Jersey: Pearson Education Inc.

Søderberg, A.-M., \& Holden, N. (2002). Rethinking cross cultural management in a globalizing business world. International Journal of Cross Cultural Management, 103-121.

Uzakbaeva, S.A. and Beisenbayeva, A., (2015). The Opportunities of Kazakh National Culture in the Formation of Value Orientations of Students. Procedia-Social and Behavioral Sciences, 185, pp.432436.

Yamada, H. (1992). American and Japanese business discourse: A comparison of interactional styles. Ablex Publishing Corporation.

Yli-Jokipii, H. (1994). Requests in professional discourse: A cross-cultural study of British, American, and Finnish business writing. Suomalainen tiedeakatemia. 